\title{
Genetic links between narcolepsy and ADHD
}

\author{
Drake D. Duane (i] ${ }^{1}$
}

Dear Editor,

In a recent issue of Translational Psychiatry, Takahashi et al. $^{1}$ reported their analysis of shared polygenic risk scores suggest a shared genetic background for both attention deficit hyperactivity disorder (ADHD) and narcolepsy. By another method, we described a similar association between ADHD and narcolepsy. In a paper delivered at the 1995 American Academy of Neurology ${ }^{2}$, we reported three families each in two generations with concurrent ADHD, hypersomnia defined by pupillometry $^{3}$ without sleep log evidence of sleep disorder and both HLA markers DR-2/DQw-1 employed at that time associated with narcolepsy (Fig. 1).

Our subsequent studies have suggested a frequency of HLA markers associated with narcolepsy more than double than anticipated in Caucasians in individuals with behavioral and cognitive evidence of $\mathrm{ADHD}^{4}$. Clinically, we have observed late adolescent ADHD patients who will

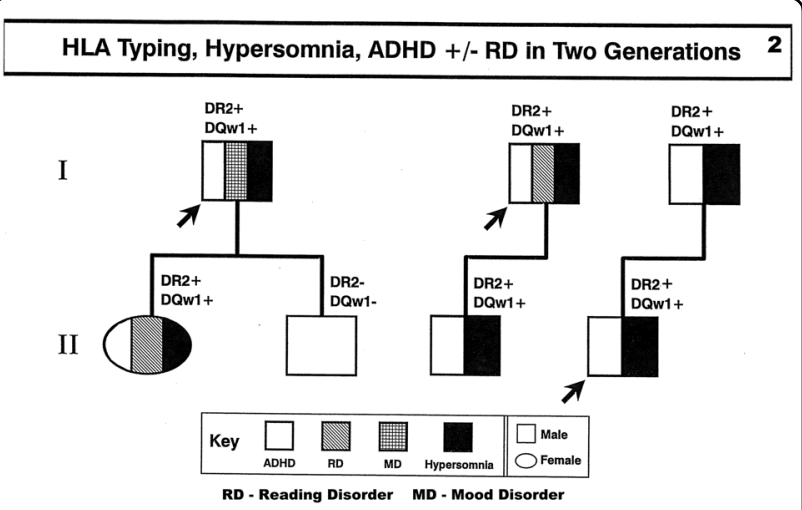

Fig. 1 HLA typing using DR-2/DQw-1 markers, hypersomnia, ADHD \pm Reading Disorder in two generations. not drive automobiles without their alerting medications for fear of falling asleep. We have additionally observed an increased frequency of these HLA markers as well as hypersomnia in individuals with dyslexia, both with and without $\mathrm{ADHD}^{5}$. However, either condition may occur independent of these HLA markers.

The social significance of such an association if valid is that an unknown percentage of ADHD children/adolescents/adults may require alerting medication to become safe adult drivers, as sleepiness increases the risk of motor vehicle accident by a factor of $2.5^{6}$.

\section{Conflict of interest}

The author declares no competing interests.

\section{Publisher's note \\ Springer Nature remains neutral with regard to jurisdictional claims in published maps and institutional affiliations.}

Received: 15 October 2020 Revised: 18 March 2021 Accepted: 6 April 2021 Published online: 28 May 2021

\section{References}

1. Takahashi, N. et al. Polygenic risk score analysis revealed shared genetic background in attention deficit hyperactivity disorder and narcolepsy. Transl. Psychiatry 10, 284 (2020).

2. Clark, M. \& Duane, D. D. HLA-typing in three families with two generations of concurrent hypersomnia and attention deficit disorder. Neurology 45, a433 (1995).

3. Yoss, R., Moyer, R. \& Ogle, K. N. The pupillogram and narcolepsy. A method to measure decreased levels of wakefulness. Neurology 19, 921-928 (1969).

4. Honda, Y. \& Juji, T. (eds). HLA in Narcolepsy (Springer-Verlag, 1988).

5. Duane, D. D., Prete, K. M., Johnson, R. \& Bailon, M. J. Alertness and HLA DR-2/ DQw-1 in ADD - inattentive, hyperactive and reading disorder patients. Unpublished observations, 1997-2021.

6. Bioulac, S. et al. Risk of motor vehicle accidents related to sleepiness at the wheel: a systematic review and meta-analysis. Sleep 40, 1-10 (2017).
Correspondence: Drake D. Duane (drakedduane@yahoo.com)

${ }^{1}$ Institute for Developmental Behavioral Neurology/Biological Psychiatry, 8585 East Bell Road, Suite 101, Scottsdale, AZ 85260, USA

\section{(c) The Author(s) 2021}

(c) OPen Access This article is licensed under a Creative Commons Attribution 4.0 International License, which permits use, sharing, adaptation, distribution and reproduction cc. in any medium or format, as long as you give appropriate credit to the original author(s) and the source, provide a link to the Creative Commons license, and indicate if changes were made. The images or other third party material in this article are included in the article's Creative Commons license, unless indicated otherwise in a credit line to the material. If material is not included in the article's Creative Commons license and your intended use is not permitted by statutory regulation or exceeds the permitted use, you will need to obtain permission directly from the copyright holder. To view a copy of this license, visit http://creativecommons.org/licenses/by/4.0/. 